\title{
Case Report: Concomitant Treatment of a Cervical Adenocarcinoma and Two Cosmetic-Gynecological Surgeries
}

\author{
Jack Pardo Schanz* \\ Clínica Ginestetica, Uroginecología y Cirugía Vaginal, Chile
}

Submission: March 14, 2019 ; Published: April 18, 2019

*Corresponding author: Jack Pardo Schanz, Clínica Ginestetica, Uroginecología y Cirugía Vaginal, Chile

\begin{abstract}
Cosmetic gynecology (CG) in its surgical and non-surgical forms has been installed in the last decade as a new subspecialty. We believe that this is the first reported case in which a major oncological gynecological surgery and CG surgeries were combined. The patient was a treated for stage Ib cervical adenocarcinoma of the cervix who underwent two CG surgeries. These surgeries were radical hysterectomy with lymphadenectomy, labiaplasty and colpoperineoplasty due to a wide vagina sensation. More than 5 years have passed and the patient is without evidence of oncological disease and highly satisfied with her CG surgeries performed. We think that in well selected cases these surgeries can be combined.
\end{abstract}

\section{Introduction}

Cosmeticgynecology (CG) has been installing step by step as another area of the gynecologist's work [1]. For many years, the author has combined classic gynecological surgeries with CG surgeries such as labiaplasty of the labia minora and mayora and vaginal rejuvenation i.e. colpoperineoplasty in women with a sensation of a wide vagina [2]. In 2016, the author published an experience of 1003 suburethral slings and their association with the mentioned cosmeto-gynecological surgeries [3]. In these 1003 patients there were 732 CG surgeries. So far the association of gynecological oncology with the concept of cosmetics was only given by the fact that we can do almost all gynecological oncologycal surgeries by laparoscopy (ovary, radical histerectomy for endometrial or cervix carcinoma), that is, preserving abdominal aesthetics avoiding large laparotomies [4].

The author has performed on many occasions CG surgeries in patients who at the same time had a conization, with a scalpel or leep, but these cases correspond to premalignant, noninvasive cancers. In our knowledge, a case in which CG surgery associated with a major oncological gynecological surgery in the medical literature has not been described. We present the case of a patient treated for a cervical adenocarcinoma who underwent CG surgery in the same surgical procedure.

\section{Case Description}

A 42-year-old patient, multipara of 3 vaginal deliveries, the last 10 months before the diagnosis of the cancer. She had a normal cervical cytology performed at the beginning of her last pregnancy. The patient complains of a symptomatic hypertrophy of the labia minora and a wide vagina sensation (vaginal laxity). In the case of the labia minora these caused discomfort from the aesthetic and functional point of view. Vaginal laxity, without prolapse, decreased pleasure during vaginal intercourse with difficulty obtaining vaginal orgasm. At the preoperative study, an important cervicitis was observed that did not respond to treatments with local antibiotics. Cytology was not performed, hoping that it would improve, but since this improvement did not occur, the author suspected cervical neoplasia and sent the patient for evaluation by an oncologist gynecologist.

The biopsy showed a well differentiated adenocarcinoma of the cervix. This measured clinically less than 3 centimeters. A pre-surgical clinical staging was performed that concluded that it was a small volume stage IB. She was presented to an oncology committee that indicated a radical hysterectomy with pelvic lymphadenectomy. At that time, the patient requested the labiaplasty and vaginal rejuvenation be performed in the same operation, which initially was rejected by the gyn-oncologists. 
At the insistence of the patient, it was accepted to perform CG surgery as long as the intraoperative findings were not an obstacle to this. It was decided to perform a contemporary biopsy of the lymph nodes and the uterus and if the tumor was located exclusively in the cervix it was accepted to complete the surgery with labiaplasty and vaginal rejuvenation. The latter would be a posterior colpoperineoplasty i.e. vaginoplasty or vaginal rejuvenation . Before proceeding, of course, the patient signed an informed consent.

Radical hysterectomy and lymphadenectomy were developped abdominally by a transverse low access and without complications. The concomitant anatomopathological study showed that the tumor was located only in the cervix and was $2,5 \mathrm{~cm}$ and was exophytic. Next, a labiaplasty of the labia minora was performed with diode laser [5] and a colpoperineoplasty also assisted with diode laser for the dissection of the rectovaginal fascia and the perineum.

All the surgery developed without complications as well as its postoperative period. After 4 days she was discharged. At six weeks she was treated locally for a small granuloma of the vaginal vault. When resuming her sexual life, the patient was completely satisfied with the aesthetic and functional result of her CG surgeries. There were serial controls during the following years by the gyn-oncology team. It has been more than 5 years since surgery so the patient is considered cured.

\section{Discussion}

Of course the case is controversial. The main concern was that the patient subsequently needed complementary therapy, specially localized radiation therapy. However, in order to avoid this situation, the anatomopathological intraoperative study was carried out, which fortunately concluded that the tumor was restricted to the cervix and was a small volume. We believe that as in all medicine, each case should be analyzed individually and that in highly studied situations we can offer CG surgery when treating a gynecological cancer patient in the early stages.

\section{References}

1. Pauls RN (2007) Nip, tuck and rejuvenate: the latest frontier for the gynecologic surgeon. Int Urogynecol J Pelvic Floor Dysfunct 18(8): 841-842.

2. Pardo JS, Solà VD, Ricci PA, Guiloff EF, Freundlich OK, et al. (2006) Colpoperineoplasty in women with a sensation of a wide vagina. Acta Obstet Gynecol Scand 85(9): 1125-1127.

3. Schanz JIP, Dalenz VS (2017) Midurethral sling combined combined with cosmetic gynecological surgeries: Our experience in 13 years. Journal of Gynecology and womens health 3(2): 1-4.

4. Stewart KI, Fader AN (2017) New Developments in Minimally Invasive Gynecologic Oncology Surgery. Clin Obstet Gynecol 60(2): 330-348.

5. Pardo J, Solà V, Ricci P, Guilloff E (2006) Laser labioplasty of labia minora. Int Journal of Gynecology and Obstetrics 93(1): 38-43.

\section{Your next submission with Juniper Publishers will reach you the below assets}

- Quality Editorial service

- Swift Peer Review

- Reprints availability

- E-prints Service

- Manuscript Podcast for convenient understanding

- Global attainment for your research

- Manuscript accessibility in different formats

( Pdf, E-pub, Full Text, Audio)

- Unceasing customer service

Track the below URL for one-step submission https://juniperpublishers.com/online-submission.php 